\title{
Microfiche as a medium for the long-term storage of laboratory computer records
}

\author{
JD MCVITTIE,* CHRISTINE WhitehOUSE, $†$ AND RH WILKINSON* \\ From the *Department of Clinical Biochemistry, John Radcliffe Hospital, Headington, Oxford OX3 9DU, \\ and the $\dagger$ Regional Computer Unit, Oxford Regional Health Authority, Old Road, Headington, Oxford, UK
}

SUMMARY The chemical pathology requests on 180000 patients a year are stored on microfiche, occupying $72 \mathrm{~mm}$ of shelf space. They are produced by a sequence of three computer programs which remove data from disc on to magnetic tape using the laboratory's Digital Equipment Corporation PDP 11/34 minicomputer. Processing on to microfiche is performed by a bureau. The magnetic tape is available for retrospective research and management studies in one-month periods.

Problems are encountered in many clinical laboratories with the storage and retrieval of laboratory reports. Department of Health and Social Security regulations state that patients' records must be preserved for at least six years-longer in the case of children-and, although there may be some truth in the argument that this applies to centralised medical records, most laboratories choose to keep their own records for as long as is practicable.

The major difficulty is the space required for longterm storage of laboratory reports, but a further factor is the amount of clerical filing required to make retrieval possible. Computerisation of laboratory data handling is a partial solution, but the need to load the storage medium on to the computer before beginning any search is a factor that precludes rapid and efficient retrieval of historic data. We describe a procedure incorporating a computerised data handling system with subsequent culling of ancient records and the production of microfiche as the ultimate long-term storage medium. The system has been in operation in our laboratory for over six months, and we believe that it minimises the problems associated with alternative procedures.

\section{Production of microfiche}

Our laboratory data handling is based on a version of the Phoenix system ${ }^{1}$ implemented on a Digital Equipment Corporation PDP 11/34 minicomputer. ${ }^{2}$ The PDP 11/34 incorporates two 14 Mbyte disc drives and two 5 Mbyte magnetic tape units. In dayto-day operation, programs and operating system information are held on one 14 Mbyte disc (the

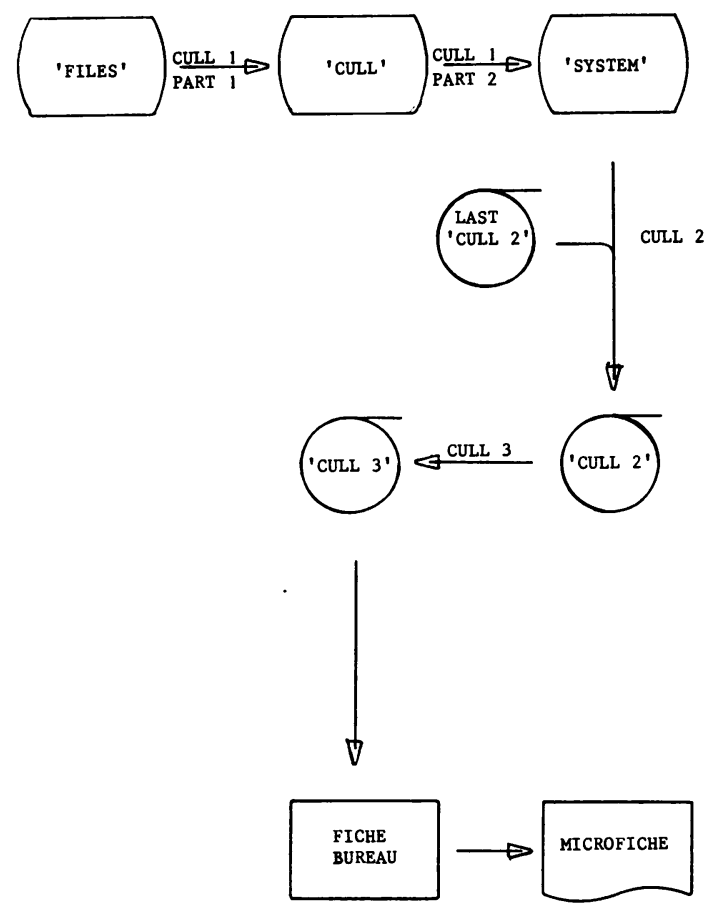

Fig. 1 Diagrammatic representation of the culling procedure. 
'system' disc), and laboratory data files are stored on the other disc (the 'files' disc). With a daily workload of 500-600 requests it is possible to hold six to eight weeks' records on the files disc. Each week a series of 'cull' programs are run in order to remove records that have been on file for more than six weeks. The procedure is summarised diagrammatically in Figure 1.

\section{CULL 1}

Data that have been on file for longer than a chosen period (usually six weeks) are removed from the current files disc and written on to another disc (the 'cull' disc). This procedure is followed by a complete file reorganisation and is conveniently carried out overnight (cull 1-part 1). The next morning the 'cull' file which has just been created is copied on to the system disc, overwriting the cull file created two weeks previously (cull 1-part 2). The culled information is thus still held on the computer and is immediately available if required until this file is itself overwritten two weeks later.

CULL 2

This program is run the morning after cull 1 and writes the cull file on to a magnetic tape. At the same time the data from this cull file can be merged with data from previous cull files held on magnetic tape (the product of previous cull 2 procedures) to produce a cumulative file of culled reports in alphabetical order of patients' surnames.

\section{CULL 3}

This program is run as soon as is convenient after the completion of cull 2 and modifies the records on the cull 2 magnetic tape into a format suitable for

\section{microgen com bureaux- WATFORD 41387/LONDON 638-0078/STOKE.ON. TRENT 410418/BRISTOL 426861}

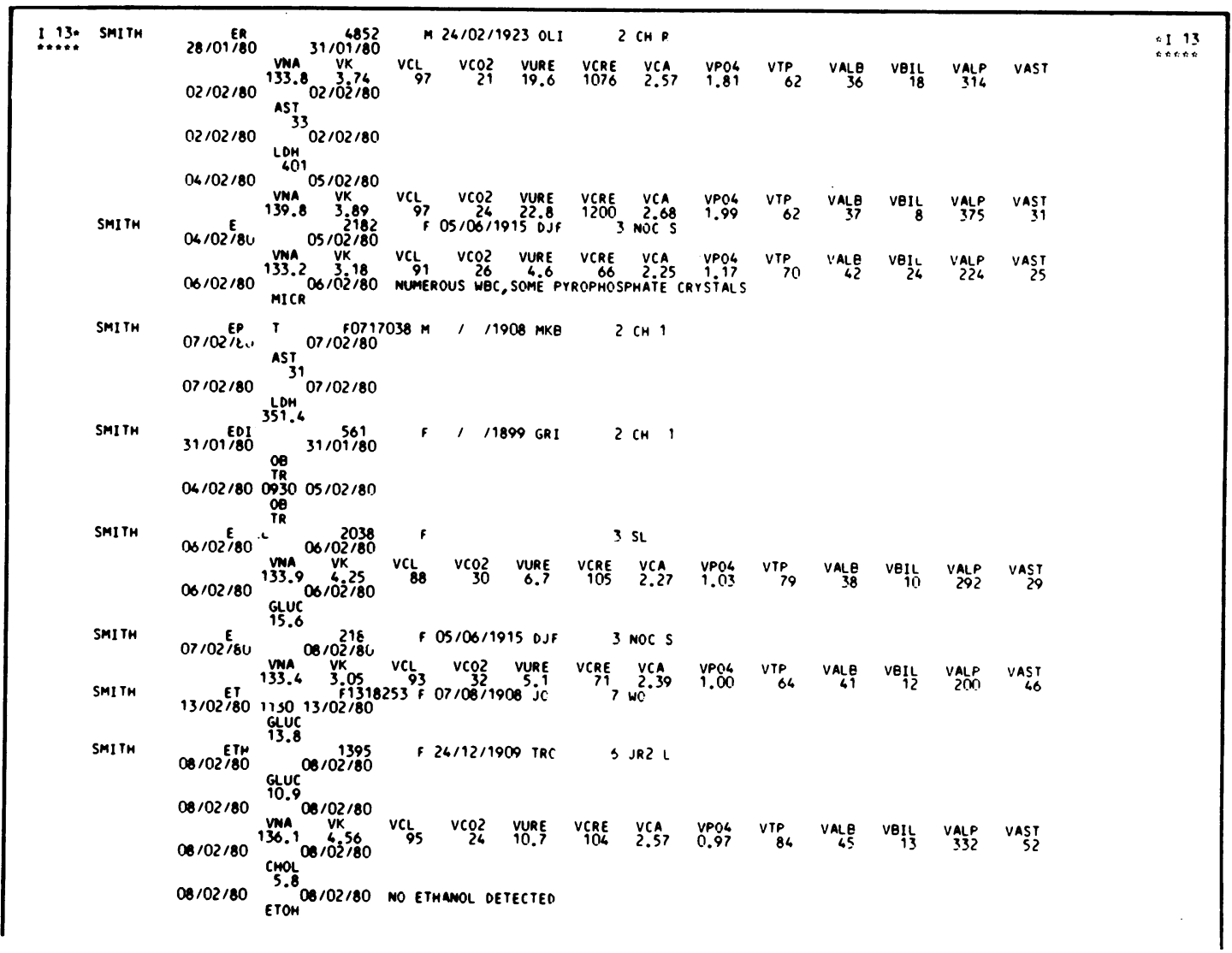

Fig. 2 Presentation of laboratory results on microfiche. Line 1: Surname, forename, case No., sex, date of birth, clinician, patient location; Line 2: date and time of collection, date and time of receipt, laboratory comment; Line 3: test codes; Line 4: results. 
Fig. 3 Presentation of laboratory results on computer VDU terminal. Patient identity details are displayed in the format. Line 1: case No., surname, forename, date of birth, sex, patient location, clinician; Line 2: laboratory No., specimen type, date and time of collection, date and time of receipt.

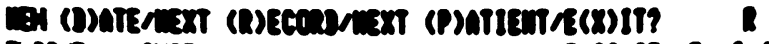

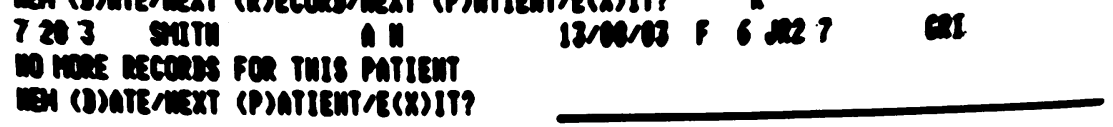

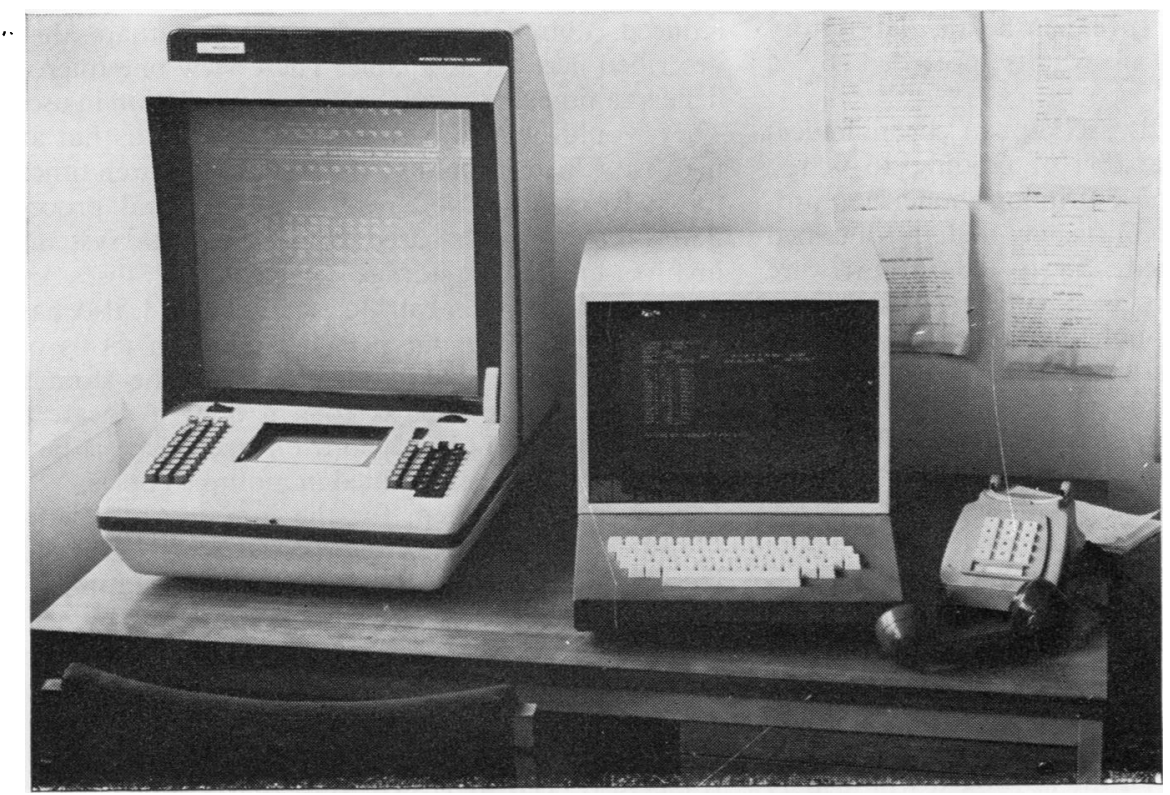

Fig. 4 The results enquiry desk comprising (left to right) automated microfiche viewer, computer $V D U$ terminal, and telephone.

processing into microfiche. The output of cull 3 is on to magnetic tape, and the tape(s) are then sent to a bureau (Microgen, 9 Langley Road, Watford, Herts) for the generation of microfiche. The microfiche and the magnetic tapes are returned rapidly, usually within two days of despatch.

In principle, it is possible to use the suite of programs described above to produce cumulative records covering any required period of time. In practice, with our computer configuration, it proves 
convenient to accumulate reports into monthly periods since if longer intervals were chosen the number of magnetic tapes to be handled during cull 2 and cull 3 would be excessive. Again, it would be possible to simplify the above procedure by, for instance, culling directly from the files disc to the system disc in cull 1. However, we believe the procedure as described to be preferable since it gives adequate security against the accidental nonrecoverable loss of data.

The use of this particular method of producing microfiche also allows us to keep the magnetic tape records produced in cull 2 for use in computer-based enquiry/reporting procedures which are proving invaluable for obtaining retrospective research and management information.

\section{Record storage and retrieval}

The compactness of microfiche records means that a very large number of records can be stored next to a microfiche viewer and be available for immediate retrieval at any time. An example of the format of the microfiche records is given in Figure 2. This can be compared with the presentation of individual patient records as displayed on the computer's visual display units shown in Figure 3. In both, the record includes patient identity details, specimen details, laboratory comment, and analytical results preceded by a codified test name.

The microfiche records are kept in chronological order in a cartridge capable of holding 26 fiches. This cartridge is part of a Bruning model 95 automated microfiche retrieval display system (obtained from Microscot Limited, Merit House, Edgware Road, London NW9). It is situated next to a computer VDU and a telephone at our results enquiry desk (Fig. 4). In answering an enquiry, the clerical officer must first ask for the approximate date of collection of the specimen in question. If this is within the previous eight weeks the results are available immediately from the computer VDU. If the specimen dates from more than seven weeks before the enquiry the results will be available on microfiche. To view the results on microfiche the operator must select the appropriate cartridge and from the cartridge title/index select which of the 26 enclosed microfiches holds the results of interest. Insertion of the cartridge into the viewer and depression of the corresponding number on the keyboard will display the index to the 207 pages of results held on that microfiche. The two or three character alphanumeric code for the required page number is then keyed in, and the page containing the required results is immediately and automatically displayed on the screen. The whole process need take no longer than 15 seconds to display any particular record of any patient for any month of any year.

\section{Discussion}

As is shown in Fig. 2, the microfiche record for each patient is four lines for the first set of results and three lines for all subsequent sets. There are 64 lines on each microfiche page and 207 pages (plus one index page) per microfiche. On average we find that we can store the results of just under 12 patient events (requests) per page or 2450 per microfiche. A laboratory workload of 500 requests a day can be completely recorded on five to six microfiches a month. Since one cartridge (dimensions $182 \times 158 \times$ $24 \mathrm{~mm}$ ) can hold 26 microfiches we find it convenient to store our results as four months to a cartridge, three cartridges a year. One year's complete laboratory records at this workload can then be stored in less than $75 \mathrm{~mm}$ of shelving.

Using our previous procedure of filing the original request cards as the laboratory record of results, one day's work would require at least $176 \times 114 \times 132 \mathrm{~mm}$ of storage space. Thus the use of microfiche records allows us to store approximately 18 months' results in the space previously occupied by one day. The retrieval time for individual results is also drastically reduced. Simpler microfiche viewers than that described here are available. These view one microfiche at a time and require more manipulation in use. They would be suitable for lower workloads but at high workloads would result in longer search times for individual results. Alternative archival procedures for computer-based laboratory data systems involve long-term storage of computer discs or magnetic tape. This can be expensive and also has disadvantages over our present system in terms of retrieval time: it takes longer to load the storage medium on the computer than it does to locate a microfiche record. The record on microfiche is permanent and may be obtained in multiple copies.

A microfiche system for the indexing of microfilmed histopathology reports has been used to increase speed of access. ${ }^{3}$ A system utilising microfiche as the archival storage medium for chemical pathology has been described, ${ }^{4}$ but in this case it was necessary to use more than one computer to effect the translation of the laboratory data files. Automated display of the microfiche was not mentioned. It has also been suggested to us that a similar effect to microfiche could be obtained by printing the historic records on to paper and then microfilming the resulting pages. This would doubtless be feasible and would preclude the necessity for magnetic tape units within the computer system. The quality of reproduction would be inferior, however, although 
production costs would be very similar. The facility of searching the magnetic tapes used in our system would be lost.

In summary, we recommend the use of microfiche as a storage medium for archival laboratory data as giving a more compact filing system and more rapid retrieval system than any other manual or computerised procedures known to us.

We thank the staff of the Department of Medical Illustration for the illustrations. We also gratefully acknowledge the support of the Oxford Regional Computer Unit.

\section{References}

${ }^{1}$ Abson J, Prall A, Wootton IDP. Data processing in pathology laboratories: the Phoenix system (1-3). Ann Clin Biochem 1977;14:307-14, 315-22, 323-9.

${ }^{2}$ Ballard B, Massey J, McVittie JD, Sharp AA, Thompson R, Wilkinson RH. 3rd European Congress of Clinical Biochemistry Abstracts 1979;36.

${ }^{3}$ Allen PW, Angus BV. Computer output microfilm in an anatomic pathology laboratory. Am J Clin Pathol 1978; $68: 537-43$.

${ }^{4}$ Pryor LR, Freeman VD. An archival system for clinical laboratory data. Am J Clin Pathol 1979;72:1013-7.

Requests for reprints to: Dr RH Wilkinson, Department of Clinical Biochemistry, John Radcliffe Hospital, Headington, Oxford OX3 9DU.

\section{Reports and Bulletins prepared by the Association of Clinical Biochemists}

The following reports and bulletins are published by the Association of Clinical Biochemists. They may be obtained from The Publishing Department, British Medical Journal (ACB Technical Bulletins), BMA House, Tavistock Square, London WCIH 9JR. Overseas readers should remit by British Postal or Money Order.

SCIENTIFIC REVIEWS (price $£ 1 \cdot 00 / \$ 2.00$ each)

1 The assessment of thyroid function March 1971 FV FLYNN and JR HOBBS

2 Renal function tests suitable for clinical practice January 1972 FL MITCHELL, N VEALL, and RWE WATTS

3 Biochemical tests for the assessment of fetoplacental function May 1975 CE WILDE and RE OAKEY

4 Test of exocrine pancreatic function March 1977 AH GOWENLOCK

5 Assay of cholinesterase in clinical chemistry March 1979 ELSIE SILK, J KING, and MARY WHITTAKER

TECHNICAL BULletins (price $£ 1 \cdot 00 / \$ 2.00$ each)

22 Bilirubin standards and the determination of bilirubin by manual and technicon AutoAnalyzer methods January 1971 BARBARA BILLING, RUTH HASLAM, and $\mathrm{N}$ WALD

23 Interchangeable cells for spectrophotometers and fluorimeters September 1971 ss BROWN and AH GOWENLOCK

24 Simple tests to detect poisons March 1972 BW MEADE $e t$ al.

25 Blood gas analysers May 1972 K DixON

26 Kits for enzyme activity determination September 1972 SB ROSALKI and D TARLOW

27 Assessment of pumps suitable for incorporation into existing continuous flow analytical systems November 1972 A FLECK et al.

28 Routine clinical measurements of transferrin in human serum September 1973 K DIXON
29 Control materials for clinical biochemistry (5th edition) September 1973 JF STEVENS

30 Notes on the quality of performance of serum cholesterol assays September 1973 SS BROWN

31 Determination of uric acid in blood and in urine July 1974 RWE WATTS

32 A survey of amino acid analysers readily available in the United Kingdom September 1974 JE CARLYLE and P PURKISS

33 Definitions of some words and terms used in automated analysis November 1974 A FLECK, R ROBINSON, SS BROWN, and JR HOBBS

34 Measurement of albumin in the sera of patients January 1975 LINDA SLATER, PM CARTER, and JR HOBBS

35 Investigation of the validity of temperature correction factors for serum aspartate and alanine transaminases March 1975 SB ROSALKI et al.

36 Factors influencing the assay of creatinine November 1975 JGH COOK

37 A survey of enzyme reaction rate analysers readily available in the United Kingdom July 1977 RA SAUNDERS and RF BURNS

38 Transport of specimens for clinical chemistry analysis November 1977 P WILDING, JF ZILVA, and CE WILDE

39 A scheme for the evaluation of diagnostic kits May 1978 PH LLOYD

40 A practical guide to gamma-counting in radioimmunoassay January 1980 CE WILDE and D OTTEWELL 41 The use of biochemical tests in the diagnosis of disorders of calcium metabolism July 1980 ANGELA FAIRNEY 